\title{
ENREDAMENTOS HISTÓRICOS DA PARTICIPAÇÃO DA ESFERA PRIVADA NA QUESTÃO SOCIAL E NO SETOR EDUCACIONAL
}

\author{
MARIA VIEIRA SILVA* \\ PaUlo Vinícius LAMANA Diniz ${ }^{* *}$
}

\begin{abstract}
Os piores senhores eram os que se mostravam mais bondosos para com seus escravos, pois assim impediam que o horror do sistema fosse percebido pelos que o sofriam, e compreendido pelos que o contemplavam. (Oscar Wilde)
\end{abstract}

\begin{abstract}
RESUMO: Nas últimas duas décadas intensificaram-se os mecanismos de intervenção do setor produtivo privado na questão social, com alcance em múltiplos espaços como a educação. O texto problematiza aspectos concernentes dessa relação mediante dois enfoques: no primeiro momento, faz apontamentos acerca das práticas e intenções sociais capitalistas ensejadas no final do século XIX e início do século XX. Posteriormente, analisa os projetos e proposições de diferentes segmentos do setor empresarial para a educação no contexto brasileiro atual. As análises evidenciam similitudes das políticas e práticas do setor privado para com a questão social em distintos contextos e enfatiza a intensificação dos processos de incrementação dos conteúdos e métodos de participação empresarial no âmbito escolar.
\end{abstract}

Palavras-chave: Questão social. Filantropia empresarial. Público e privado na educação.

\section{THE PRIVATE SECTOR'S HISTORICAL PLOT FOR PARTICIPATION IN THE SOCIAL AND EDUCATIONAL SECTORS}

ABSTRACT: In the last two decades the intervention mechanisms of the private sector in social issues have been intensified, ranging across multiple areas such as education. The text discusses aspects concerning this relationship through two approaches: the first deals with the historical moment of transition from economic individualism to the programmatic economy with

\footnotetext{
* $\quad$ Faculdade de Educação da Universidade Federal de Uberlândia (UFU). Uberlândia (MG) - Brasil.

** Universidade Federal de Uberlândia (UFU). Uberlândia (MG) - Brasil.

Contato com os autores: <mvs@ufu.br>
} 
emphasis on the social practices of capitalist management, vested in the late nineteenth and early twentieth centuries. It subsequently reviews projects and proposals for education in the current Brazilian context from different segments of the business sector. The analysis reveals similarities between the policies and practices of the private sector regarding social issues in different contexts and emphasizes the intensification of the processes of institutionalization of the "company with a soul" at the present time by the increment in the manner and method of business participation in schools.

Key words: Public and private sectors partnerships. Capitalist philanthropy. Social issues.

\section{INTERVENTION HISTORIQUE DE LA PARTICIPATION DU SECTEUR PRIVE DANS LA QUESTION SOCIALE ET DANS LE SECTEUR SCOLAIRE}

RÉSUMÉ: Pendant les dernières deux décennies se sont intensifiés les mécanismes d'intervention du secteur privé dans la question sociale, en s'étendant dans de multiples sphères comme celle de l'éducation. Le texte souligne les aspects de cette relation selon deux approches : d'abord le moment historique, on analyse les pratiques et les intentions sociales capitalistes épiées à l'occasion de la fin du XIX siècle et début du XX siècle. Ultérieurement, on analyse les projets et les propositions de différents segments du secteur privé pour l'éducation dans le contexte brésilien actuel. Les analyses prouvent les similitudes des politiques et des pratiques du secteur privé envers la question sociale dans de distincts contextes et soulignent l'intensification des processus d'augmentation des contenus et les méthodes de participation du secteur privé dans le contexte scolaire.

Mots-clés: Question sociale. La philanthropie capitaliste. Public et privé dans l'éducation.

\section{Introdução}

$\mathrm{A}$

s contradições e ambiguidades da caridade e filantropia praticada pelos capitalistas são recorrentes em distintos momentos. Destarte, tal intervenção na questão social, longe de ser uma atuação fortuita e pontual, se plasma em estratégias de caráter orgânico e estrutural do desenvolvimento do capital como relação social e guarda conexões, em maior ou menor escala, com os mecanismos de controle e disciplina do trabalho para garantir a incrementação dos processos de exploração na produção. Tendo como referência a relativização das condições materiais presentes entre temporalidades distintas, as reflexões presentes neste artigo apresentam os nexos existentes nas ações e proposições dos capitalistas de diferentes contextos históricos, colocando em relevo os paradoxos, contradições e ambiguidades no trato da questão social. Assim, na primeira seção, enfocamos práticas sociais dos gestores capitalistas em contextos anteriores. Na segunda seção, analisaremos aspectos da intervenção de segmentos do setor empresarial para a educação nas últimas duas 
décadas. Para tanto, analisaremos os enredamentos discursivos do setor empresarial, publicados em diferentes veículos de ampla divulgação nacional, tais como cartilhas, documentos de entidades, anais de eventos e premiações.

\section{A participação empresarial na esfera social: antecedentes históri- cos da arquitetura política}

A chamada "questão social" surge no debate político do século XIX em decorrência das consequências negativas, já naquela altura extremamente visíveis, do processo de urbanização e industrialização, principalmente na França e Inglaterra. Solange Mercier-Josa (1998) afirma que a questão social aparece nos termos da época como a questão da sorte da "classe mais numerosa e mais pobre" (Saint Simon); como a "pobreza que nasce em civilização de abundância", da "miséria da multidão industriosa" (Charles Fourier); da "humilhação do povo privado de seus imprescritíveis direitos, o sofrimento popular, a fome, a nudez, a agonia popular" (F. de Lammenais), entre outros. Interessa-nos destacar que o termo acaba por expressar as dimensões deploráveis do pauperismo intrínsecas à dialética do desenvolvimento societal capitalista. Nesse sentido, questão social remete-nos à ideia do acirramento dos problemas e da situação social e econômica dos trabalhadores.

Por obra e pressão das lutas sociais, os trabalhadores conseguiram minimizar os efeitos degradantes da questão social e conquistar algumas de suas demandas por meio de políticas "públicas" referentes à habitação, saúde, educação, previdência, seguridade social etc., pela mediação do Estado. Muito embora a classe capitalista contribua sistematicamente para o agravamento da questão social, há em diferentes contextos históricos uma rede de apoio paralela à atuação estatal (sociedade política), por meio de doações, ajudas e práticas caritativas para intervenção na esfera social.

Em um estudo datado de 1844-1845, em que examinava de maneira pormenorizada a situação da classe operária inglesa, Friedrich Engels caracterizava as precárias condições de sobrevivência dos operários:

[...] A sociedade inteiramente atomizada não se preocupa com eles, atribuindo-lhes o encargo de prover suas necessidades e as de suas famílias, mas não lhes oferece os meios para que façam de modo eficaz e permanente. [...], as casas dos operários estão mal localizadas, são mal construídas, mal conservadas, mal arejadas, úmidas e insalubres; seus habitantes são confinados num espaço mínimo e, na maior parte dos casos, num único cômodo vive uma família inteira; o interior das casas é miserável: [...] A comida é frequentemente ruim, muitas vezes imprópria, em muitos casos - pelo menos em certos períodos - insuficiente e, no limite, há mortes por fome [...]. (ENGELS, 2008, p. 115) 
Engels (op. cit., p. 42) chamava a atenção para o fato de que a existência de vida do proletariado era ignorada e menosprezada pela burguesia: “[...] até mesmo as filantrópicas 'Associações para Elevação das Classes Laboriosas' - nas quais, hoje, nossa burguesia despreza a questão social - incorporam as mais ridículas e absurdas opiniões sobre a situação dos operários". Talvez o autor acreditasse que, em algum momento, fosse possível à burguesia assumir, incorporando opiniões fundamentadas em outra ótica - que não a sua própria -, os problemas sociais. Porém, afastando-se de tal possibilidade, o autor reconhece em outra obra que:

\begin{abstract}
Quanto mais progride a civilização, mais se vê obrigada a encobrir os males que traz necessariamente consigo, ocultando-os com o manto da caridade, enfeitando-os ou simplesmente negando-os. Em resumo, introduz uma hipocrisia convencional que sequer era conhecida pelas primitivas formas de sociedade e pelos primeiros estágios da civilização [...]. (Engels, 2006, p. 188-189)
\end{abstract}

Sob tal perspectiva, também em A situação da classe trabalhadora na Inglaterra, o autor elucida os limites e contradições da caridade burguesa:

\begin{abstract}
Não se creia, porém, que o inglês "culto" expresse tão cruamente seu egoísmo. Ao contrário, ele o dissimula com a mais vil das hipocrisias. Como falar da insensibilidade desses ricos burgueses diante dos pobres, se eles criaram instituições de beneficência que não existem em nenhum outro país? Beneficência... Bela filantropia a dessa classe que, para ajudar ao proletariado, começa por explorá-lo até a última gota de sangue para, em seguida, lançar sobre ele sua complacente e farisaica beneficência e, dando aos infelizes menos que a centésima parte do que lhes retirou, apresentar-se ao mundo com a aparência de campeã da caridade! [...]. (ENGELS, 2008, p. 309)
\end{abstract}

Dada a precarização da vida dos trabalhadores, mas também por força dos enfrentamentos e instabilidades sociais a que o pauperismo e a degradação das condições de vida levavam, a burguesia por vezes se via na necessidade de socializar uma parte ínfima da riqueza socialmente produzida, por meio de ações beneficentes, as quais funcionavam como forma de controle e contenção da indignação. Como arma na luta de classes, a empresa capitalista historicamente tem convertido uma parcela da mais-valia extraída em caridade, ajudas tópicas em certas áreas sociais.

Antônio Gramsci, nas primeiras décadas do século XX, também se aproximou da discussão sobre a intervenção dos capitalistas na "questão social" e nos oferece elementos importantes para pensarmos a atualidade por meio de suas análises sobre o Rotary Clube. O ensaio Americanismo e fordismo reunia as preocupações do autor acerca da emergência de um "novo" padrão de relações industriais e de acumulação capitalista no mundo ocidental. Tratava-se, para Gramsci (2001), de compreender o surgimento dos novos grupos dirigentes e suas formas de exercer a dominação econômica, política e intelectual em suas relações com a classe trabalhadora. Para o 
autor, o fordismo e o americanismo derivavam da necessidade imanente de organizar uma economia programática e que os diversos problemas examinados deveriam ser os elos da cadeia que assinalam exatamente a passagem do velho individualismo econômico para a economia programática.

Para Gramsci (op. cit.), o fordismo não dizia respeito a uma mera fórmula estritamente técnica de gestão da produção, tratava-se antes de um projeto de dominação de classe e que, portanto, perpassava todas as esferas da vida social, inclusive a da cultura. É sob tal perspectiva que se situam suas críticas ao Rotary Club, entendido como uma das estratégias do "americanismo". Tal entidade foi fundada nos Estados Unidos em 1905 e, historicamente, se caracterizou por ser uma organização dos grupos que dispunham de maior poder aquisitivo. Gramsci caracteriza o Rotary Club como um grupo de homens de negócios e profissionais liberais, os quais, sem juramentos secretos nem dogmas ou credos, aceitam a filosofia do serviço:

[...] Parece que o seu programa essencial baseia-se na difusão de um novo espírito capitalista, na ideia de que a indústria e o comércio, antes de ser um negócio, são um serviço social; ainda mais, são e podem ser um negócio na medida em que representam um "serviço". Assim, o Rotary desejaria que o "capitalismo de rapina" fosse superado e se instaurasse um novo costume, mais propício ao desenvolvimento das forças econômicas. (2001, p. 295-296)

Esta nova filosofia e espírito capitalista, diz Gramsci, buscou unir todos os associados, independente de credo religioso, em torno de um objetivo comum: a prestação de serviços. Tal filosofia representaria assim uma superação orgânica da maçonaria e de outras formas de assistencialismo pautadas e movidas por crenças e conviç̧ões religiosas e possibilitar-se-ia a filiação de pessoas de diversos credos, religiosos ou não, desde que alinhadas em torno da ideia da indústria como um serviço.

Ainda segundo o autor, o código moral rotariano, aprovado num congresso em St. Louis (EUA), baseava-se no princípio de o clube ser fundamentalmente uma filosofia da vida que pretendia conciliar: "o eterno conflito existente entre o desejo de cada um de ganhar e o dever e consequente impulso de servir ao próximo" (GRAMSCI, op. cit., p. xx). Resumia-se da seguinte forma a filosofia do serviço no referido código: "dar de si antes de pensar em si, baseada no princípio moral: quem serve melhor ganha mais" (idem, ibid.). O componente ético-político da filosofia rotariana - de que os capitalistas, apesar de "privados" ("particulares") servem aos interesses "públicos" ("gerais") - expressa a tendência intrínseca às organizações do capital, imprimindo sua própria lógica de entendimento societário a todas as instituições e sujeitos sociais. Daí a multiplicação de associações e institutos empresariais que pensam e refletem não somente a vida interna das empresas, mas o conjunto da sociedade. 
Avançando no século XX, na década de 1960, o polonês Paul A. Baran e o estadunidense Paul M. Sweezy, em seu estudo Capitalismo monopolista, se empenharam em mostrar a mudança do regime competitivo analisado por Marx, que se baseava num grande número de pequenas empresas disputando no mercado a preferência dos consumidores, para o regime monopolista marcado pela supremacia das grandes empresas ligadas entre si por uma rede de instituições financeiras que passavam a ocupar o centro da dinâmica capitalista. O desaparecimento do filantropo capitalista individual - aquele homem bondoso que doava de tempos em tempos quantias em dinheiro nas solenidades públicas para as mais diversas instituições demandantes da sociedade -, em decorrência de sua substituição pela "administração", não significava o desaparecimento da caridade capitalista, que passaria então a ser cada vez mais institucionalizada, ou seja, racionalizada pela empresa:

[...] ela está sendo institucionalizada e, embora até o momento as fundações se tenham destacado, as próprias empresas estão desempenhando um papel cada vez mais importante [...]. Sem dúvida, estão certos os observadores que identificam nisso uma tendência que continuará no futuro indefinido; por fim, talvez, o custo de quase toda filantropia privada recairá diretamente sobre as grandes companhias. (BARAN; SWEEZY, 1966, p. 54)

Na visão dos autores, a ocupação empresarial com a questão social traz consigo fundamentalmente o elemento das "relações públicas", ou seja, tornar a empresa mais bem vista pelo público com quem se relaciona; melhorar sua imagem ("marca") perante a sociedade, tornando assim mais estreitos os vínculos, no imaginário social, entre vida empresarial e comunitária.

Tragtenberg (1980) também faz apontamentos importantes acerca da ação empresarial quando estuda os postulados dos ideólogos das grandes corporações. Berle, por exemplo, "acredita firmemente nas 'harmonias econômicas', na identidade de interesses entre a sociedade e a grande corporação, desenvolvendo daí o conceito de empresa-comunitária" (TRAGTENBERG, op. cit., p. 12). Nesta direção, assegura que "a corporação é reflexo de valores e atitudes que se desenvolveram inusitadamente, permitindo o salto da fase do barão assaltante para a empresa com responsabilidade social" (idem, ibid.). Seus preconizadores defendem que, embora a corporação vise à maximização de seus lucros - e, de fato, maximiza-os com projetos em longo prazo -, ela é uma obra de organização social e "isso permite a ela assumir o mecenato artístico e a filantropia social" (ibid., p. 16).

Essa tendência ganhou materialidade de forma mais incisiva na realidade brasileira nos anos de 1990, por meio da atuação do empresariado em uma dimensão específica da questão social: a educação. Pautados na premissa do êxito da relação tríade entre educação escolar, desenvolvimento econômico e expansão do capital, os 
empresários começaram a dirigir mais fortemente o foco de sua atuação social para o setor educacional, conforme veremos na seção que se segue.

\section{Empresa e escola: o discurso e as proposições do setor empresarial no tempo presente}

Nas últimas duas décadas, a partir das novas configurações no mundo do trabalho, os discursos empresariais, em sintonia com as proposições governamentais e com a maioria das centrais sindicais, indicaram que, diante das mudanças em curso, o novo perfil do trabalhador requer uma qualificação mais complexa e diferente das exigidas pelos modelos produtivos tradicionais. Essa qualificação poderá advir de uma escolarização que garanta o desenvolvimento das habilidades requeridas pelo novo conteúdo do trabalho, para suprir as lacunas e deficiências existentes na implementação dos atuais processos tecnológicos e organizacionais.

Para tanto, os diversos setores demonstram por meio de suas proposições a preocupação com a elevação do nível de escolarização como forma de capacitar a força de trabalho para as mudanças na economia globalizada. Nessa direção, o Instituto de Estudos de Desenvolvimento Industrial (Iedi) produziu um documento intitulado A nova relação entre competitividade e educação: estratégias empresariais, o qual aborda exclusivamente o problema da defasagem educacional dos trabalhadores brasileiros. O documento ressalta que os mecanismos de seleção da mão de obra tendem a valorizar o raciocínio lógico, a capacidade de decisão e de resolução de problemas, a cooperação e a capacidade de aprender do trabalhador. Como esses atributos não são adquiridos por meio dos conteúdos de educação básica, o texto ressalta o papel fundamental dos investimentos nessa área.

Tal perspectiva de análise é reiterada por Silva Filho, coordenador de projetos na área educacional do Instituto Herbert Levy (IHL). Segundo ele, para se integrar no contexto da época atual e exercer eficazmente um papel na área econômica,

[...] o indivíduo tem que [...] interpretar a realidade, expressar-se adequadamente, lidar com conceitos científicos e matemáticos abstratos, trabalhar em grupos na resolução de problemas relativamente complexos, entender e usufruir das potencialidades tecnológicas do mundo que nos cerca. E, principalmente, precisa aprender a aprender, condição indispensável para poder alcançar as mudanças e avanços cada vez mais rápidos que caracterizam o ritmo da sociedade moderna. (1996, p. 88)

Entre os objetivos do referido Instituto, estão os de apoiar e gerenciar projetos nas áreas de meio ambiente e educação e atuar junto ao Comitê de Educação da Comissão Empresarial de Competitividade (CEC). Esse Instituto foi criado durante o governo Collor através de decreto presidencial e foi constituído por cerca de 210 
empresários que representavam segmentos do setor produtivo de todos os estados do Brasil. Na concepção de seu coordenador, a primeira tarefa do instituto "foi colocar para o comitê a importância do ensino fundamental, enfatizando que aí estava o gargalo do sistema educacional brasileiro" (SILVA FILHO, 1996, p. 87). Ressalta ainda que "nenhum país se arrisca a entrar em competição por mercados internacionais sem haver antes estabelecido um sistema educacional, onde a maioria da população tenha atingido um mínimo de 8 a 10 séries de ensino de boa qualidade" (idem, ibid.).

O coordenador do IHL assegura que a participação direta do empresário no trato das questões da educação e da escola é importante por três razões: porque familiariza o empresário com essas questões; porque no estado atual da educação brasileira é útil complementar a ação do governo; e porque é a empresa que mais ganha, quando a comunidade onde se insere melhora seu padrão educacional. Nessa linha de raciocínio, o coordenador sugere que, “além da participação direta, o empresário pode atuar localmente, participando da gestão da escola, e, através das confederações, que têm acesso ao poder, propor e cobrar políticas educacionais" (idem, ibid.).

Para a viabilização dessa participação, o IHL propõe que os empresários conheçam o tema "ensino fundamental" e, com esse objetivo, elaborou, juntamente com a Fundação Bradesco, o trabalho Ensino fundamental e competitividade empresarial - uma proposta para ação do governo. Ao se reportar à importância da avaliação escolar, o documento faz uma comparação mecânica e linear entre o produto do mundo dos negócios e os sujeitos da aprendizagem:

\footnotetext{
No mundo dos negócios, cada vez que um produto fica pronto, toda empresa séria verifica se aquele produto corresponde às especificações que deve ter para ser entregue aos consumidores. Controlar a qualidade de tudo que é produzido é uma atividade de rotina. É natural que, em algo tão importante quanto à educação, os empresários esperem que o governo proceda da mesma forma, ou seja: que antes de entregar os alunos à sociedade, verifique se aprenderam o que precisam saber, de acordo com as especificações estabelecidas pelo governo para cada nível de ensino. Trata-se da mesma ideia de controle da qualidade. (INSTITUTO HERBERT LEVY, 1996, p. 47)
}

Ainda no âmbito empresarial, o exame de alguns documentos elaborados pela Confederação Nacional da Indústria (CNI) indica também a ênfase atribuída à escola básica como requisito fundamental para o desenvolvimento econômico ao afirmar: "[...] a contribuição de pessoas com sólida educação básica e boa formação profissional assume, portanto, papel central na economia, constituindo-se em fator fundamental da riqueza das nações" (CONFEDERAÇÃO NACIONAL DA INDÚSTRIA, 1996b, p. 5).

Em conformidade com essa crença, a Confederação consolidou em seus espaços oficiais debates seguidos de proposições do segmento empresarial para a escola 
básica. Em um estudo intitulado Custo Brasil, produzido em 1996, a Confederação apresenta as bases do pensamento empresarial para elevar a capacidade do país de enfrentar a concorrência internacional.

Partindo do pressuposto de que a deficiência do desempenho escolar afeta significativamente a competitividade da economia nacional, no documento Competitividade: proposta dos empresários para a melhoria da qualidade da educação (1996), os empresários propõem como macroprioridades para a superação da crise educacional brasileira: a educação básica, como foco principal das estratégias de melhoria da qualidade da educação; a valorização do professor, por meio da melhoria da sua formação e da sua remuneração; a implantação da gestão da qualidade nas escolas, fortalecendo os sistemas de avaliação em todos os níveis e modalidades da ação educativa; a ampliação de oportunidades e o aperfeiçoamento da educação e da requalificação profissionais, para acompanhar as mudanças tecnológicas e assegurar o desenvolvimento econômico e social; a contribuição efetiva da universidade na formação do magistério para a educação básica e no desenvolvimento da competitividade industrial.

A partir dessas "macroprioridades", o documento sistematiza suas propostas detalhadamente e dirige-se aos diferentes segmentos, propondo ações destinadas à educação básica, à educação profissional, ao ensino superior, à capacitação e requalificação de adultos e à gestão e tecnologia. Para cada um desses níveis há especificações que dizem respeito ao "âmbito estrutural", dirigidas aos governos federal, estaduais e municipais; ao "âmbito setorial", envolvendo a cooperação e a parceria entre empresas, entidades empresariais, instituições de ensino públicas e privadas e órgãos de governo; e ao "âmbito de cada empresa".

No âmbito dos estados da Federação, Minas Gerais esteve na vanguarda desse movimento norteado pelo Projeto Pró-Qualidade e pela implementação do sistema de parceria entre empresa e escola, o qual foi encaminhado pelo segmento empresarial e pela Secretaria Estadual de Educação de Minas Gerais na gestão do então secretário Walfrido dos Mares Guia. Em uma síntese do relatório do Pacto de Minas pela Educação, lançado em 31 de janeiro de 1994, foi publicada uma relação de 134 empresas e sua atuação nas respectivas cidades onde estão sendo desenvolvidos seus trabalhos nas escolas. O órgão catalisador e mediador das iniciativas empresariais para a educação foi a Federação das Indústrias do Estado de Minas Gerais (Fiemg). O então secretário estadual da Educação, Walfrido dos Mares Guia, ao defender também a prioridade para o ensino fundamental, pauta-se em estudos que indicam que uma mesma quantia investida no ensino fundamental gera um retorno muito maior para os indivíduos beneficiados e para a sociedade do que a mesma soma aplicada no ensino universitário. 
Os discursos dos setores empresarial e governamental estão em plena sintonia. Movidos por interesses comuns, o empresariado da iniciativa privada em Minas Gerais aparece como sujeito proponente de iniciativas e projetos educacionais que se operacionalizam diretamente no interior das escolas públicas e atendem à solicitação feita pelo secretário de Educação:

Como empresários, os senhores devem apoiar os programas de adoção de escolas públicas. Tal adoção não deverá ser apenas uma forma de canalizar recursos para a Escola. Deve ser também uma oportunidade para que os empresários se familiarizem com as questões da educação e com os problemas das classes mais desassistidas da população. A adoção pode e deve ser conduzida de forma a motivar a comunidade a participar do dia a dia da Escola. A presença da empresa facilitará a continuidade de programas bem concebidos em períodos de mudança de governo. A experiência gerencial dos empresários poderá ainda ser de grande valia para as escolas públicas motivadas em aperfeiçoar a sua administração. (MARES GUIA, 1993, p. 25)

Naquele contexto, a entidade de representação máxima do empresariado mineiro foi solícita a tal convocação. Nesse sentido, o então presidente do Conselho de Educação da Fiemg afirma que o papel da Federação na concretização dessa visão é "sensibilizar e conscientizar o empresariado para o indispensável comprometimento com a educação básica, tendo em vista a dimensão social e a dimensão econômica, em que se situam dois objetivos nacionais cruciais para o futuro do Brasil" (NEIVA, 1998, p. 5). Ele assevera ainda que:

[...] na dimensão social, temos que corrigir as diferenças sociais intoleráveis, se almejamos construir a cidadania e a dignidade da pessoa. Na dimensão econômica, temos que inserir o Brasil no mercado global com força de competitividade, se almejamos preservar a nossa soberania e a sobrevivência das empresas brasileiras. Por tudo isso, a Fiemg incentiva e apoia a formação de parcerias entre empresas e escolas públicas. (Idem, ibid.)

As estreitas vinculações assumidas nas relações entre o setor empresarial e o setor escolar são emblemáticas da nova configuração do Estado, ensejadas pelo acirramento da simbiose entre a esfera pública e a esfera privada. Destarte, as formulações de Bernardo (1991) trazem importantes contribuições para pensarmos em tais nexos.

O autor distingue duas configurações do Estado: Estado Restrito e Estado Amplo. Na sua concepção, o Estado Restrito imprime as clássicas funções designadas pelos poderes Legislativo, Executivo e Judiciário e tem seu campo de ação demarcado no processo particularizado da economia. Assim, o Estado Restrito assumiu um relevante papel articulador em contextos nos quais as unidades econômicas se encontravam em processo de particularização e isolamento recíproco. Nesta direção, as atribuições do Estado Restrito ascendem e se legitimam quanto maior for a fragmentação do funcionamento das unidades econômicas. 
Quanto ao Estado Amplo, a terminologia criada por Bernardo é por si só elucidativa da abrangência do seu conceito, pois em sua definição, o Estado Amplo é constituído pelos mais variados mecanismos de produção da mais-valia. Nesta direção, as empresas compõem e são componentes do Estado Amplo, uma vez que é no seu interior que são produzidos os princípios de administração da produção capitalista, a gestão da força de trabalho e a lógica de produção de mercadorias. Processos estes que ocorrem de forma dinâmica, inter-relacionada e em constante mutação, por meio da atuação dos gestores. São eles que detêm o poder de planejar e controlar tanto as unidades produtivas quanto as condições gerais de produção, mediante os saberes que detêm sobre os processos organizacionais. Sob tal perspectiva, o que caracteriza o declínio do Estado Restrito e a ascensão do Estado Amplo é a transnacionalização da economia. A partir do desenvolvimento e articulação das unidades econômicas e das condições gerais de produção, há um arrefecimento de um e ascensão do outro.

Sob tal ótica, o processo de declínio do Estado Restrito e ascensão do Estado Amplo constitui um dos elementos determinantes na nova organização do mundo do trabalho que surge sob a mundialização do capital. Na esfera da política, instaura-se uma nova subjetividade para o trabalhador, por meio de mecanismos que provocam rupturas ou declínios na perspectiva da identidade de classe pela absorção da lógica do capital. São múltiplos e complexos os mecanismos utilizados para a materialização, o desenvolvimento e a expansão do conteúdo ideológico do Estado Amplo; um deles tem sido a instituição escolar, conforme revela a participação do segmento empresarial na dinâmica escolar da realidade mineira, mediada por representantes do poder estatal.

Em meados dos anos de 1990, um número expressivo de empresas mineiras aderiu às proposições e à conclamação da Fiemg e da Secretaria de Estado da Educação de Minas Gerais para desenvolver o projeto de parcerias entre empresas e escolas. Assim se manifestou o diretor-presidente da Cia. Siderúrgica Belgo Mineira, naquele contexto:

\footnotetext{
Precisamos melhorar a capacitação da mão de obra, se quisermos atingir um grau de competitividade igual à dos nossos concorrentes internacionais, condição essencial para exportarmos e atingirmos o tão desejado crescimento sustentado da economia. Para isto é necessário investir com urgência na educação; educação e crescimento econômico são fundamentais para elevar a renda per capita da força de trabalho, a chave para melhorar a qualidade de vida dos nossos trabalhadores de todos os níveis. É preciso destinar uns $20 \%$ do PIB para a educação, com o fim de provocar aquele salto qualitativo absolutamente necessário para tornar o nosso país mais competitivo e para recuperarmos o atraso que temos em relação aos países desenvolvidos. (MOYEN, [1990?], p. 16)
}

Ainda de acordo com o empresário, a deficiência educacional é um dos muitos componentes do tão criticado e nocivo "Custo Brasil" e prejudica a competitividade 
das empresas nacionais. Reiterando os princípios da teoria do capital humano, Moyen ressalta ainda que o crescimento econômico do país depende, sobretudo, da elevação da taxa de instrução. Assim,

\begin{abstract}
Nós empresários temos o dever de insistir e de tentar, por todos os meios, convencer a sociedade e a classe política que o principal obstáculo ao crescimento econômico, a médio prazo, já não são as políticas estruturais, mas a educação. O esforço que o país requer tem de começar agora [...]. Repito: a educação é a chave não só para acelerar o crescimento econômico e a competitividade das nossas empresas, mas também para aliviar os problemas da pobreza e da desigualdade social. (Idem, ibid.)
\end{abstract}

A empresa Acesita, por meio das assertivas de seu presidente em 1997, também corroborou essa tendência:

\begin{abstract}
Ou todos nós buscamos e desenvolvemos soluções para os nossos problemas e criamos condições para mudarmos a sociedade, através de parcerias que envolvam os setores público e privado e a população como um todo, ou este país não vai se desenvolver [...]. Entendemos que não é possível se ter desenvolvimento social sem ações concretas no setor educacional. A Fundação Acesita, ao invés de construir uma escola, optou por desenvolver um programa de Melhoria da Qualidade do Ensino em todas as escolas de Timóteo. (BRUMER, 1997, p. 14)
\end{abstract}

Souza, por ocasião do Prêmio Fiemg "Nansen Araújo", apresenta objetivos ainda mais pragmáticos no argumento em defesa da parceria empresa-escola para ambas as instâncias e na propaganda de seus benefícios:

Está em curso uma crescente iniciativa de parceria entre empresa e escola. Isso é de fundamental importância, pois a escola poderá absorver da empresa as várias experiências de gestão administrativa e de pessoal. E poderá, evidentemente, melhorar suas condições, ao receber da parceria trabalho voluntário e doação de equipamentos. Em contrapartida, a empresa poderá aumentar a sua produtividade, além de estar demonstrando a sua preocupação social e, ao mesmo tempo, melhorando a sua imagem pública. Ela só tem a ganhar com esse procedimento, pois, além de formar uma população mais educada e qualificada, a empresa estará diminuindo infinitamente os seus custos de treinamento. (SOUZA, [190-?], p. 21)

As narrativas presentes nesses documentos elaborados pelo setor empresarial são reveladoras da criação do consenso entre o vínculo entre escolarização/qualificação profissional e competitividade/desenvolvimento, sedimentado pelo binômio "Economia e Educação". Tal proposição não é movida por injunções do senso comum, mas fundamentada pela teoria do capital humano. Segundo os postulados de Shultz (1962, apud FRIGOTTO, 1986, p. 40), “o componente da produção, decorrente da instrução, é um investimento em habilidades e conhecimentos que aumenta futuras rendas e, desse modo, assemelha-se a um investimento em (outros) bens de produção". Nessa linha de raciocínio, à educação - tida como investimento - é 
imputada a função potenciadora de trabalho, pois o indivíduo, dotado de capital humano, possibilita uma taxa de retorno que se reverte em maior produtividade e, consequentemente, em maior desenvolvimento econômico. Assim, o conceito de capital humano - ou, mais extensivamente, de recursos humanos - busca traduzir o montante de investimento que uma nação faz ou os indivíduos fazem, na expectativa de retornos adicionais futuros. Do ponto de vista macroeconômico, o investimento no "fator humano" passa a significar um dos determinantes básicos para aumento de produtividade e elemento de superação do atraso econômico. Do ponto de vista microeconômico, constitui-se no fator explicativo das diferenças individuais de produtividade e de renda e, consequentemente, de mobilidade social (FRIGOTTO, 1986). Em termos gerais, a teoria do capital humano parte do suposto que a forma como um indivíduo investe ou distribui seu tempo entre as várias atividades do presente influencia em sua produtividade futura. Disso decorre a grande ênfase na educação, ou escolarização, como fator imprescindível de ascensão individual pela mobilidade social e crescimento econômico. Contrapondo-se a essa perspectiva, acreditamos que, para além de tais argumentos, as principais motivações da participação do empresariado na educação pública são a consolidação e materialização da lógica dos "quase mercados". A noção de "quase mercado" propaga a ideia de que "tanto do ponto de vista operativo, quanto conceitual, diferencia-se da alternativa de mercado propriamente dita, podendo, portanto, ser implantada no setor público sob a suposição de induzir melhorias" (PORTELA; SOUZA, 2003, p. 877).

Assim sendo, a conformação da educação escolar à nova fase de produção da mais-valia tem contribuído de forma significativa para a proliferação de políticas, tendo como referenciais paradigmas advindos do neoliberalismo e a consolidação de uma figura jurídica nova: o terceiro setor. Segundo Paoli (2002), o "terceiro setor" reivindica um modelo de regulação social mais eficaz do que o realizado pelo Estado, a ser realizado, portanto, em outro lugar: a sociedade civil, composta por uma grande diversidade de ações, atores e organizações que se unificam pela recusa em pertencer ao âmbito do Estado e do mercado. Assim, na expansão do terceiro setor, propõe-se de fato outro modelo para a resolução da questão social - centrado na generalização de competências civis descentralizadas, exercidas pelo ativismo civil voluntário em localidades específicas. Nesse sentido, o novo trato à questão social é alterado significativamente: está sendo retirada paulatinamente da órbita do Estado, sendo privatizada.

Destarte, é preciso relativizar a dita "não lucratividade" dessas entidades. Segundo Montaño (2003), algumas fundações que se configuram em braços assistenciais de empresas não podem esconder seu claro interesse econômico por meio da isenção de impostos, ou da melhora da imagem de seus produtos. Agregar valor social à marca é um fato inerente às ações e projetos sociais desenvolvidos pelas 
empresas, visando à lucratividade de forma indireta expressa pela isenção de impostos e marketing. Segundo Paoli (2002), a utopia da responsabilidade social do empresariado torna-se então conservadora porque, por mais sensível que seja às desigualdades sociais, preserva ao mesmo tempo as hierarquias desiguais que produzem a descapacitação dos cidadãos, ao recriá-los como cidadãos de segunda e terceira classes, dependentes da caridade da ação externa privada para possibilidade da inclusão social. Dependem, portanto, das intenções, dos interesses e das flutuações, dos acertos e dos enganos próprios do mundo mercantil e inerentes à liberdade com que, afinal, foi cunhada há dois séculos a expressão "iniciativa privada", contra a qual se formaram os espaços públicos diferenciados, críticos e propositivos, voltados para a emancipação ampliada de um mundo comum.

\section{Considerações finais}

O conteúdo dos discursos relatados explicita que os nexos propostos para o setor empresarial e a escola são de caráter genuinamente econômico-ideológico, frente aos dispositivos impostos pela competitividade do mercado e sob influência da ideologia neoliberal. Ademais, o conteúdo dessas falas busca a legitimação da crença na educação como redentora dos complexos problemas estruturais como a pobreza e a desigualdade social, que historicamente tiveram esse mesmo agente, o empresariado, como coautor ou partícipe. A correlação entre educação e sistemas produtivos como via para o desenvolvimento econômico requer um olhar focalizado sobre a forma como ela vem ocorrendo. Partimos do suposto que a participação do empresariado na gestão da escola pública não está provida apenas de um cariz técnico e operacional para garantir sua eficiência e produtividade ou de ações movidas pela dimensão assistencialista, mas contém um forte conteúdo ideológico referente ao papel da educação escolar. Este conteúdo opera na esfera cultural e da política com alguns desdobramentos: A conformação da organização do trabalho pedagógico ao reordenamento político e econômico do mundo do trabalho, mediante a veiculação dos aparatos culturais da lógica empresarial; a formação do trabalhador economicamente desejável, segundo os desígnios do pensamento empresarial expressos no currículo formal e oculto da escola; a ocupação de forma sistematizada da escola pública pelo setor produtivo privado e a simbiose entre a educação escolar e o mercado de trabalho numa perspectiva pragmática; a garantia da legitimidade da empresa no plano subjetivo, mas com resultados objetivos em seu processo de acumulação.

A intervenção empresarial não incide apenas de forma objetiva na gestão da escola, mas também por meio de atitudes transmitidas pelos conhecimentos não manifestos que disciplinam e ordenam as ações dos agentes educacionais, e também por meio de ritos de poder que qualificam e desqualificam, incluem e excluem, permitem 
ou negam, definem o certo e seu oposto, os bons e os maus, os exitosos e os fracassados. O que está presente no interior desta dinâmica é o estabelecimento das conexões entre a dinâmica escolar e a dinâmica empresarial, provocando um ajustamento da escola ao universo mercantil segundo os desígnios do capital.

A dimensão ideológica incide por meio de múltiplos aspectos, sobretudo mediante a conformação da organização do trabalho pedagógico aos aparatos culturais da lógica empresarial e a formação do trabalhador economicamente desejável, segundo os desígnios do pensamento empresarial. Nesta direção, é apropriado remeter à conclusão de Tragtenberg (1980, p. 28), ao afirmar que "empresa não é só o local físico onde o trabalho excedente cresce às expensas do necessário, o palco da oposição de classes; é também o cenário da inculcação ideológica. Nesse sentido, empresa é também aparelho ideológico". São múltiplos e complexos os mecanismos utilizados para a materialização, o desenvolvimento e a expansão do conteúdo ideológico da esfera empresarial na instituição escolar. Tal instituição, sobretudo no atual momento de transnacionalização da economia, torna-se uma aliada fundamental para sua personificação do poder.

No decorrer dessas reflexões, o que esteve em foco foi apenas um ângulo do conflito, que diz respeito ao modo pelo qual são operados alguns aspectos das novas configurações do público e privado, os quais incidem na esfera escolar. Não podemos negar, todavia, a existência das dinâmicas de resistência, manifestas ou tácitas, que se consolidam na prática social mais ampla e no cotidiano da escola e contribuem para a transgressão, a alteração ou a desconstrução do discurso hegemônico do capital que circula na escola, entre outros espaços.

\section{Referências}

BARAN, P.A.; SWEEZY, P.M. Capitalismo monopolista. Rio de Janeiro: Zahar, 1966.

BERNARDO, J. Economia dos conflitos sociais. São Paulo: Cortez, 1991.

BRUMER, W.N. Empresários. In: Parceria empresa-escola: Prêmio Fiemg "Nansen Araújo". Belo Horizonte: Fiemg, 1997.

CONFEDERAÇÃO NACIONAL DA INDÚSTRIA (CNI). Custo Brasil. Rio de Janeiro: CNI, 1996a.

CONFEDERAÇÃO NACIONAL DA INDÚSTRIA (CNI). Competitividade: proposta dos empresários para a melhoria da qualidade da educação. Rio de Janeiro: CNI/ Sesi/Senai/IEL, 1996b.

ENGELS, F. A situação da classe trabalhadora na Inglaterra. São Paulo: Boitempo, 2008. 
FIEMG. Conselho de Educação do Sistema Fiemg. Parceria empresa-escola: desenvolvimento e cidadania. Belo Horizonte: Fiemg, [1995?].

FRIGOTTO, G. A produtividade da escola improdutiva: um (re)exame das relações entre educação e estrutura econômico-social capitalista. 3. ed. São Paulo: Cortez; Campinas: Autores Associados, 1986.

GRAMSCI, A. Temas de cultura: ação católica; americanismo e fordismo. Trad. de C. N. Coutinho, L. S. Henriques e M. A. Nogueira. Rio de Janeiro: Civilização Brasileira, 2001.

INSTITUTO DE ESTUDOS DE DESENVOLVIMENTO INDUSTRIAL (IEDI). Mudar para competir: a nova relação entre competitividade e educação. Estratégias Empresarias. [s.1.]: Iedi, [1992?].

INSTITUTO HERBERT LEVY (IHL). Ensino fundamental e competitividade empresarial: uma proposta para ação do governo. São Paulo: IHL, 1996.

MARES GUIA, W. Educação e desenvolvimento: conscientização, vontade política, participação. In: CONGRESSO BRASILEIRO DE FINANCIAMENTO DO DESENVOLVIMENTO, 1., 1993, São Paulo. Anais... São Paulo: ABDE, 1993.

MERCIER-JOSA, S. Marx, o político e o social. Crítica Marxista, São Paulo, n. 6, p. 7-21, 1998.

MOYEN, F. Empresários. In: Parceria empresa-escola: Prêmio Fiemg “Nansen Araújo". Belo Horizonte: Fiemg, [1990?].

MONTAÑO, C. Terceiro setor e questão social: crítica ao padrão emergente de intervenção social. São Paulo: Cortez, 2003.

NEIVA, E. Prefácio. In: Parceria empresa-escola: Prêmio Fiemg "Nansen Araújo". Belo Horizonte: Fiemg, 1998.

PAOLI, M.C. Empresas e responsabilidade social: os enredamentos da cidadania no Brasil. In: SANTOS, B.S. (Org.). Democratizar a democracia: os caminhos da democracia participativa. Rio de Janeiro: Civilização Brasileira, 2002.

PORTELA, R.; SOUZA, S.Z.L. Políticas de avaliação da educação e quase mercado no Brasil. Educação E Sociedade, Campinas, v. 24, n. 84, p. 873-895, set. 2003.

SILVA FILHO, H.P. O empresariado e a educação. In: FERRETTI, C.J. et al. (Org.). Novas tecnologias, trabalho e educação: um debate multidisciplinar. 3. ed. Petrópolis: Vozes, 1996. 
SOUZA, C.R. Educadores. In: Parceria empresa-escola: Prêmio Fiemg “Nansen Araújo". Belo Horizonte: Fiemg, [190-?].

TRAGTENBERG, M. Administração, poder e ideologia. São Paulo: Moraes, 1980.

Recebido em 11 de abril de 2012.

Aprovado em 30 de julho de 2013. 